This document is published in:

Economic Theory (1997), 10 (3), pp. 463-482.

Doi: http://www.dx.doi.org/10.1007/s001990050167

(C) 1997 Springer-Verlag 


\title{
Uninsured idiosyncratic risk, liquidity constraints and aggregate fluctuations
}

\author{
Javier Díaz-Giménez \\ Departamento de Economía, Universidad Carlos III de Madrid, Calle Madrid 126, \\ E-28903 Getafe, SPAIN
}

Received: March 6, 1996; revised version August 15, 1996

Summary. I study the role played by uninsured idiosyncratic risk and liquidity constraints in the propagation of aggregate fluctuations. To this purpose, I compare the aggregate fluctuations of two model economies that differ in their insurance technologies only. In one of these model economies liquidity constrained households vary their holdings of a nominally denominated asset in order to buffer an uninsured idiosyncratic shock to their individual production opportunities. In the other economy every idiosyncratic component of risk can be costlessly insured. I find that the limited insurance technology implies fluctuations in output that are $20 \%$ larger, fluctuations in hours relative to output that are 9\% larger, fluctuations in consumption relative to output that are $18 \%$ smaller, and a correlation of hours and productivity that is $15 \%$ smaller than those that obtain under the full insurance technology.

JEL Classification Numbers: D58, E21, E32, E44.

\section{Introduction}

In the last twenty years representative household models have been successfully used to address issues in fields as diverse as growth theory, business cycles, public finance and monetary economics. Central to these models is the assumption that the decisions of every household in the economy can be aggregated into a single, stand-in household. To make this aggregation possible, representative household models, implicitly assume that every idiosyncratic component of risk is completely and costlessly insured. In the real world, we have ample evidence that this is not the case.

\footnotetext{
*This paper has benefitted greatly from the insights and advice of E.C. Prescott. I thank the Institute of Empirical Macroeconomics for providing supercomputer time. Conversations with Larry Christiano, T.J. Kehoe, Tryphon Kollintzas, Ramon Marimon and José-Victor Ríos-Rull, the comments of one anonymous referee, and financial support from the Sloan Foundation and the DGICYT are also gratefully acknowledged.
} 
Even in the most advanced of modern industrial economies the set of idiosyncratic contingencies that are formally insured is limited. One of the reasons that justifies some of these insurance limitations is the existence of private information. Another related reason is the high cost of many insurance contracts. In 1989, for example, the insurance sector contributed 2\% of ths U.S. value added. Uninsured contingencies and the high cost of insurance provide important incentives for risk averse agents to find alternative ways to smooth their consumption streams.

One of these alternative ways is to use borrowing and lending to smooth out uninsured variations in household income. In the real world, however, there is also evidence, that many households have limited opportunities to engage in non-collateralized borrowing against future income. Zeldes (1989), for example, finds strong microeconomic evidence that liquidity constraints affect a significant fraction of households in the United States.

When households are liquidity constrained, one way in which they can smooth out their flows of consumption is to build up their savings in periods when their income is high and to use those savings to finance their consumption in periods when their income is low. One can conjecture that M2 assets are held in part for this purpose. If we take this conjecture to be true, the large size of M2 holdings ${ }^{1}$ suggests that this precautionary motive might well have quantitatively important business cycle implications.

The main purposes of this paper are i) to quantify the business cycle behavior of a model economy in which households are liquidity constrained and vary their holdings of a nominal asset as a buffer against uninsured income fluctuations, and ii) to compare the business cycle behavior of this model economy with the one that obtains in a similar economy where every idiosyncratic component of risk can be costlessly insured.

In the two model economies that I study in this paper households have identical endowments and concave preferences, and every period each household faces the same household-specific productivity process that determines the market value of its time. Consequently, in the two economies the households face employment opportunities that are both householdspecific and potentially time varying. Finally, in both economies, households face identical sequences of economy-wide disturbances, they are precluded from borrowing against future income and the government must finance identical streams of government consumption. The only aspect in which the two economies differ is in their insurance technologies which I now describe.

In the limited insurance economy I assume that there is no insurance technology that allows households to enter into contracts contingent on the realizations of the household-specific productivity process. I also assume that households are prevented from borrowing against their future income. Given

${ }^{1}$ In the United States, for example, M2 holdings have averaged about one year of aggregate private consumption during the post-Korean War period. 
these assumptions, I show that in this class of model worlds, households choose to hold a nominally denominated asset issued by the government ${ }^{2}$.

The idiosyncratic component of the productivity shock leads different households to accumulate and deplete their asset holdings at different rates. Consequently, the state of the economy is characterized by a time-varying endogenous distribution of households ${ }^{3}$. The resulting high dimension of the state makes the use of standard recursive computational methods impractical. To get around this problem, I assume that the government targets the pricing process on the asset as part of its policy arrangement ${ }^{4}$. Under this specification of government policy, prices no longer depend on the distribution of households, and the household decision rules can be computed using standard numerical methods.

In the full insurance economy I assume that there is a technology that allows contracts conditional on the realizations of the idiosyncratic productivity shock to be enforced. Furthermore, an event-contingent scheme that eliminates all but aggregate uncertainty is assumed to exist. Given that households are ex-ante identical and risk averse, they enter into a contract that equates the marginal utility of their consumption streams regardless of their household-specific state. In this model economy I also assume that no nominal assets are held ${ }^{5}$.

I calibrate the limited insurance model economy to U.S. data and I find that the limited insurance technology implies fluctuations in output that are $20 \%$ larger, fluctuations in hours relative to output that are $9 \%$ larger, fluctuations in consumption relative to output that are $18 \%$ smaller, and a

${ }^{2}$ With these assumptions I am effectively following Sheinkman and Weiss (1986), İmrohoroğlu (1989), Díaz-Giménez and Prescott (1996), Díaz-Giménez, Prescott, Fitzgerald and Alvarez (1992), and others. An excellent survey of the economies in these last three papers can be found in Ríos-Rull (1995). An alternative way to depart from the full insurance assumption is to consider highly stylized models and to link the structure of the financial contracts to features of the underlying economy. This approach is followed, amongst others, by Atkeson and Lucas (1992), Green (1987), Green and Oh (1992), Phelan (1989), Phelan and Townsend (1992) and Marcet and Marimon (1995). Note that the holdings of this asset allow the households to substitute in part for the consumption smoothing role of insurance.

${ }^{3}$ Note that when there is no aggregate uncertainty, it can be shown that, for policies that result in a constant inflation rate similar to the ones considered in this paper, the equilibrium path of this distribution of households converges to a steady state distribution. This property simplifies the computational problem considerably.

${ }^{4}$ Note that a consequence of this type of targetting is that the process on government consumption is determined residually. For a detailed discussion of the role played by the government, see Section 2.2 and 2.4 below.

${ }^{5}$ Note that the essence of this paper is to compare the aggregate fluctuations that arise in an economy with an insurance technology that allows individual households to substitute consumption intertemporally incurring in a cost (the real return on the nominal asset is nonpositive), with those that obtain in an economy where the consumption risks are spread contemporaneously amongst all households, and in which the intertemporal margin is shut down. 
correlation of hours and productivity that is $15 \%$ smaller than those that obtain under the full insurance technology.

The rest of the paper is organized as follows: In Sections 2 and 3, respectively, the limited insurance and the full insurance model economies are formally described, the equilibrium processes are defined and calibration issues are discussed. Section 4 describes the computational experiments and reports the main findings. Finally, Section 5 offers some concluding comments and provides some suggestions for future research.

\section{The limited insurance economy}

\subsection{Information}

There is an exogenous economy-wide stochastic process $\left\{z_{t}\right\}$. This process is a Markov chain and its transition probabilities are:

$$
\pi_{z}\left(z^{\prime} \mid z\right)=\operatorname{Pr}\left\{z_{t+1}=z^{\prime} \mid z_{t}=z\right\} .
$$

for $z, z^{\prime} \in Z=\left\{1,2, \ldots, n_{z}\right\}$. I assume that the Markov chain generating $z$ is such that it has a single ergodic set, no transient states and no cyclically moving subsets.

Each household also faces an idiosyncratic random disturbance, $\left\{s_{t}\right\}$, that affects its individual production possibilities. These idiosyncratic disturbances are assumed to be independent and identically distributed across households. The processes for these household-specific production shocks are also assumed to follow a finite-state Markov chain with transition probabilities given by:

$$
\pi_{s}\left(s^{\prime} \mid s\right)=\operatorname{Pr}\left\{s_{t+1}=s^{\prime} \mid s_{t}=s\right\} .
$$

where $s, s^{\prime} \in S=\left\{1,2, \ldots, n_{s}\right\}$. I assume that the Markov chain generating $z$ is such that it has a single ergodic set, no transient states and no cyclically moving subsets.

The joint processes on $(s, z)$ are therefore Markov chains with $n=n_{s} \times n_{z}$ states. Their transition probabilities are:

$$
\pi\left[\left(s^{\prime}, z^{\prime}\right) \mid(s, z)\right]=\pi_{s}\left(s^{\prime} \mid s\right) \pi_{z}\left(z^{\prime} \mid z\right)
$$

Households know the laws of motion of both $\left\{s_{t}\right\}$ and $\left\{z_{t}\right\}$. At the beginning of each period they observe the realizations of both stochastic processes. Trade ensues.

\subsection{The government sector}

The government in this economy taxes labor income at a rate $\theta$. This is a proportional tax and it is assumed to be time invariant. The government also issues a nominally denominated asset, $A$. This asset determines the unit of account and it bears no interest.

Variable $p_{t}$ is the price of one unit of the date $t$ composite good expressed in units of the nominal asset. The process on $p_{t}$ is denoted by $\varepsilon\left(z_{t}\right)=p_{t+1} / p_{t}$ 
and it is determined by government policy. To implement this policy, the government exchanges goods for the asset at the policy implied price $p_{t}^{6}$. A government policy rule is, therefore, a specification of $\{\theta, \varepsilon(z)\}$, and the associated processes on government consumption, $g$, and on the government supply of the nominal asset, $A_{g}$. Under this specification for government policy, the nominal version of the government budget constraint is the following:

$$
p_{t} g_{t}+A_{g t}=\theta y_{t} p_{t}+A_{g, t+1}
$$

where $y_{t}$ denotes the aggregate output of period $t$.

This specification of government policy can have two different interpretations. First we can think of it as an inflation and nominal interest rate targetting policy similar in essence to the policies followed by many governments and central banks in the real world. An implication of this type of targetting in the model economy is that the process on government consumption is determined residually ${ }^{7}$. An alternative interpretation of the model economies' $g$ is to consider it as the sum of government consumption and net exports in a small open economy whose government borrows and lends abroad to finance its budget. A technical discussion of government policy and of the procedure used to compute the implied process on $g$ can be found in the definition of equilibrium below.

\subsection{The household sector}

\section{Preferences}

I assume that at each point in time the economy is inhabited by a large number, actually a measure one continuum, of households. These households order their random streams of consumption and leisure according to:

$$
\sum_{t=0}^{\infty} \beta^{t} u\left(c_{t}, \tau-n_{t}\right)
$$

where $u$ is a continuous and strictly concave utility function, $0<\beta<1$ is the time-discount factor, $c_{t}$ is the perishable household consumption good which is restricted to being non-negative, $\tau$ is the household endowment of productive time, and $n_{t}$ is time allocated to market activities. Hence, $\tau-n_{t}$ is time allocated by the household to non-market activities, which I call leisure.

Productive opportunities

A household's date $t$ production of the composite good is:

$$
w\left(s_{t}, z_{t}\right) n_{t}
$$

where $w\left(s_{t}, z_{t}\right)$ is that household's technology parameter. When a household chooses to work, it is paid its marginal product. Therefore $w\left(s_{t}, z_{t}\right)$ equals the

\footnotetext{
${ }^{6}$ Note that this pricing policy is restricted to being a function of the current value of the economy-wide shock, $z_{t}$, only.

${ }^{7}$ Moreover, I find that this implied process on $g$ is significantly volatile (see the discussion in Section 4 below).
} 
household's real wage. Following Rogerson (1988) and Hansen (1985), I assume a labor indivisibility. Labor services, $n_{t}$, are constrained to belonging to the set $\{0,1\}$, where zero corresponds to not being employed and one corresponds to being employed.

\section{Monetary arrangements}

I assume that in this model economy households can hold integer amounts of the nominal asset $A \in \mathscr{A}=\left\{0,1, \ldots, n_{A}\right\}$. The holdings of this asset act as a substitute for the costly insurance. These holdings are constrained to being non-negative to explore the business cycle implications of imposing an extreme form of liquidity constraints.

\section{The households' decision problem}

Let $A_{t+1}$ denote the end-of-period holdings of the nominal asset and $A_{t}$ the beginning-of-period holdings of the nominal asset, then the nominal version of the household competitive decision problem is the following:

$$
\max _{c_{t}, n_{t}, A_{t+1}} \sum_{t=0}^{\infty} \beta^{t} u\left(c_{t}, \tau-n_{t}\right)
$$

subject to the budget constraint

$$
p_{t} c_{t}+A_{t+1} \leq A_{t}+p_{t} w\left(s_{t}, z_{t}\right) n_{t}(1-\theta) .
$$

The maximization is also subject to $A_{t+1} \in \mathscr{A}$ and $n_{t} \in\{0,1\}$, and $A_{0}$ is given.

Let $a^{\prime}=A_{t+1} / p_{t}$ denote household real currency holdings valued in terms of the current period's consumption good, then the functional equation for the dynamic program solved by an $(a, s)$-type household is the following:

$$
v(a, s, z)=\max _{a^{\prime}, c, n}\left\{u(c, \tau-n)+\beta \sum_{s^{\prime}, z^{\prime}} v\left(a^{\prime}, s^{\prime}, z^{\prime}\right) \pi\left[\left(s^{\prime}, z^{\prime}\right) \mid(s, z)\right]\right\}
$$

subject to the budget constraint

$$
c+a^{\prime} \leq a / e(z)+w(s, z) n(1-\theta)
$$

where $c \geq 0, a^{\prime} \in \mathscr{A}_{\rho}=\left\{0, \rho, 2 \rho, \ldots, n_{a} \rho\right\}$ where $\rho$ denotes the real value of one unit of currency, and $n \in\{0,1\}$. Since the household's problem is a finitestate, discounted dynamic program, an optimal stationary Markov plan always exists. This optimal plan and the stochastic processes on $(s, z)$ define an ergodic transition probability matrix on $\mathscr{A}_{\rho} \times S \times Z$.

\subsection{Definition of equilibrium}

In the nominal asset market the government is not small and, therefore, I do not treat it as a price-taking agent. Instead, part of the specification of the economy is the policy arrangement employed. This explicit policy arrangement includes the following features: a description of the markets that operate and of the liquidity constraints that are imposed on households; the price $p_{t}$ at which the government exchanges the consumption good for the nominal asset; the law of motion of these prices $p_{t+1}=p_{t} \varepsilon\left(z_{t}\right)$, and the 
process on the income tax, $\theta$. For such an arrangement a definition of a recursive competitive equilibrium is the following:

The state of a household is the triple $(a, s, z)$. The measure of households of type $(a, s)$ is $x(a, s)$, and $x$ denotes the corresponding measure. The economy-wide state is the pair $(x, z)$.

An equilibrium for a policy arrangement $\{\varepsilon(z), \theta\}$, given $x_{0}$, consists of four basic parts: a government policy $\left\{g(x, z), a_{g}(x, z)\right\}$, a household policy $\left\{c(a, s, z), n(a, s, z), a^{\prime}(a, s, z)\right\}$, an inflation rate process $e(z)$, and a law of motion for the measures of household types $x_{a^{\prime} s^{\prime}}^{\prime}=f_{a^{\prime} s^{\prime}}\left(x, z, z^{\prime}\right)$ such that:

i) Given the processes on $\theta$ and $e(z)=p_{t} / p_{t-1}$, the household policy solves the household's optimization program described in equations (9)-(10) above.

ii) The goods market clears:

$$
\sum_{a, s} x(a, s) c(a, s, z)+g(y, z)=\sum_{a, s} x(a, s) n(a, s, z) w(s, z)
$$

for all $(x, z)$ in the support of the distribution of $\left(x_{t}, z_{t}\right)$ for some $t$.

iii) The asset market clears:

$$
a_{g}(x, z)=\sum_{a, s} x(a, s) a^{\prime}(a, s, z)
$$

for all $(x, z)$ in the support of the distribution of $\left(x_{t}, z_{t}\right)$ for some $t$.

iv) Household and aggregate behavior are consistent:

$$
f_{a^{\prime}, s^{\prime}}\left(x, z, z^{\prime}\right)=\sum_{a, s \in \Omega\left(a^{\prime}, z^{\prime}\right)} x(a, s) \pi\left[\left(s^{\prime}, z^{\prime}\right) \mid(s, z)\right]
$$

for all $\left(a^{\prime}, s^{\prime}, x, z, z^{\prime}\right)$ where $\Omega\left(a^{\prime}, z^{\prime}\right)=\left\{(a, s): a^{\prime}=a^{\prime}(a, s, z)\right\}^{8}$.

v) The behavior of endogenous variables is consistent with the policy arrangement. For our class of policy arrangements, this requires $e(z)=\varepsilon(z)$ and $g(x, z) \geq 0$ for all $(x, z)$ in the support of the distribution of $\left(x_{t}, z_{t}\right)$ for some $t^{9}$.

For the set of policy arrangements that I consider, there is at most one equilibrium. The computational procedure used to find the equilibrium is the following: first I solve the household problem, which is a finite-state discounted dynamic program. Then I use the household optimal decision rules and the initial distribution of households to obtain a stochastic realization of $g(x, z)$ from (11). If $g_{t}=g\left(x_{t}, z_{t}\right)$ turns out to be a positive stochastic process, the unique equilibrium for the given policy arrangement has been found. Otherwise, it has been established that no equilibrium exists for that policy

\footnotetext{
${ }^{8}$ Note that $f_{a^{\prime} s^{\prime}} \equiv\left(x^{\prime}, a^{\prime}, s^{\prime}\right)$ for all $\left(a^{\prime}, s^{\prime}\right) \in \mathscr{A}_{\rho} \times S$.

${ }^{9}$ Note that the households' budget constraints and the market clearing conditions imply that the government budget constraint is also satisfied. Expressed in real terms the budget constraint satisfied by the government is the following: $g_{t}=\theta y_{t}+a_{g t}-a_{g, t-1} / e_{t}$.
} 
arrangement. A fully documented version of the FORTRAN program used to solve this economy is available from the author upon request.

\subsection{Calibration}

I calibrate the model economies' parameters so that the size of the deviations of logged output from trend in the baseline model economy is close to that of the U.S. economy in the 1954-89 period. The definitions of the model aggregates and of the time series considered in this paper are contained in Appendix 1. The parameters that specify the government policy are different for different experiments and I discuss them in Section 4. The remaining calibration choices are the following:

\section{Time period}

Most of the U.S. time are reported quarterly. Wages, however, are paid more frequently. The model period, therefore should be shorter than a quarter of a year. I choose the model period to be an eighth of a year. This choice allows for some temporal aggregation and it keeps computational costs within reasonable bounds ${ }^{10}$.

\section{The economy-wide exogenous process}

I assume that the model economy goes through periods of good and bad times. Consequently, the aggregate process, $z$, takes two values, $z \in\{1,2\}$, where state $z=1$ represents good times and state $z=2$ represents bad times. The transition probabilities on the aggregate process determine the average duration of each of the shocks. In the U.S., business cycles last on average for about four years (for example, Delong and Summers, 1977) and the durations of expansions and recessions are roughly the same. I choose the transition probabilities on $z$ so that the model economy business cycles mimic these features. Consequently, the average duration of both good and bad times in the model economy is about two years which corresponds to sixteen model periods. Given that the expected duration of a state is the reciprocal of $1-\pi(z, z)$, where $\pi(z, z)$ is the probability of state $z$ occurring again the following period, the transition probabilities for the economy-wide process that satisfy these conditions are the following:

$$
\begin{array}{lll} 
& z^{\prime}=1 & z^{\prime}=2 \\
z=1 & 0.9375 & 0.0625 \\
z=2 & 0.0625 & 0.9375
\end{array}
$$

The household-specific exogenous processes

I assume that the individual-specific productivity processes takes two possible values, $s \in\{1,2\}$. State $s=1$ represents high productivity draws and state $s=2$ represents low productivity draws, for example a qualified electrician who can only find a job as a janitor. The transition probabilities are chosen so that, on average, 92 percent of the time households experience the

${ }^{10}$ During the calibration stage of this project I experimented with shorter model periods and I found that they did not result in significant changes in the aggregate properties of the model. 
high productivity shock and the remaining 8 percent of the time they experience the low productivity shock. I also require that the expected duration of the low productivity shock is of two model periods, or a quarter of a year. These values roughly match an approximation to the average U.S. employment rate and the expected duration of unemployment in U.S. business cycles. The transition probabilities on the individual-specific process that satisfy these requirements are the following ${ }^{11}$ :

$$
\begin{array}{lll} 
& s^{\prime}=1 & s^{\prime}=2 \\
s=1 & 0.9565 & 0.0435 \\
s=2 & 0.5000 & 0.5000
\end{array}
$$

\section{Preferences}

Following the applied general equilibrium tradition I choose a utility function with constant elasticity of substitution in consumption and leisure. During the last 50 years, in the U.S., per capita leisure has remained virtually constant, per capita consumption has grown at an average rate of nearly 2 percent, and real wages have increased by a factor of two. To match these observations I assume a unit elasticity of substitution between consumption and leisure. The utility function for our model economies is, therefore, the following:

$$
U\left(c_{t}, \tau-n_{t}\right)=(1-\sigma)^{-1}\left\{\left[c_{t}^{\alpha}\left(\tau-n_{t}\right)^{1-\alpha}\right]^{1-\sigma}-1\right\}
$$

where $\tau-n$ is leisure.

I select preference parameters $\beta=0.995$ and $\alpha=0.33$. These parameter values imply an annual subjective time discount rate of 4 percent and a share of leisure of approximately two-thirds. These values for the time discount rate and for the share of leisure are in line with observations from national income and product accounts on the net real rate of return on capital and on the average fraction of productive time that households allocate to the market. For the relative risk aversion coefficient, I choose $\sigma=1.5$. This value is commonly used in applied general equilibrium exercises in public finance and business cycle theory. The choice of $\tau$ reflects the fact that the average workweek including commuting time is roughly 45 hours, or approximately 45 percent of people's weekly endowment of $14 \times 7=98$ hours of productive time. Parameter $\tau$ is, therefore, $1 / 0.45=2.22$.

\section{Productive opportunities}

The values of the model economy productivity parameters, $w(s, z)$ are normalized so that the average productivity of highly productive types is 1.0. The relative size of the marginal productivities of households in their high and low productivity times is approximately three. This number is chosen to match the ratio between the average hourly wage in manufacturing and the minimum hourly wage in the U.S. With this choice I am implicitly assuming

11 These transition probabilities for the household-specific processes are the same as those considered in İmrohoroğlu (1989). 
that there are always minimum wage openings for anyone who wants them. Finally, the variances of the productivity parameters in good and bad times are chosen so that, given the transitions on the exogenous processes, the average standard deviation of the baseline economy's log detrended aggregate output series is close to the corresponding statistic for the U.S. economy in the post-Korean war period. The resulting productivity parameters are the following:

$$
\begin{array}{ccccc} 
& s=1, z=1 & s=1, z=2 & s=2, z=1 & s=2, z=2 \\
w(s, z) & 1.0081 & 0.9919 & 0.33673 & 0.327657
\end{array}
$$

\section{Units and bounds}

In addition to the parameters already discussed, in order for the program described in equations (9) and (10) to be well defined I must choose the real value of one unit of the nominal asset, $\rho$, and the maximum number of units of the asset, $n_{a}$. In every experiment I choose $\rho=0.008$ and $n_{a}=500$. This results in a unit of account which is approximately 0.12 percent of per capita yearly income of the baseline model economy. If I take U.S. per capita income to be $\$ 20,000$, the unit of account in the model economies would be worth approximately $\$ 24$. I find this unit to be sufficiently small for the purposes of this paper. Making this unit smaller raises the computational costs significantly and has virtually no effect on the aggregate properties of the model. Finally, the choices for parameters $\rho$ and $n_{a}$ imply that the maximum value of total asset holdings is 4 . This value is sufficiently large so that the constraint $a \in \mathscr{A}_{p}$ is never binding in equilibrium.

\section{The full insurance economy}

To offer a suitable term of comparison I also analyze the business cycle behavior of another economy which only differs from the economy described above in the insurance technology. Specifically, in the full insurance economy I assume that there is a technology that makes it possible for contracts conditional on the realizations of the household-specific productivity shocks to be enforced. Moreover an event-contingent scheme that eliminates all but aggregate uncertainty is assumed to exist. This scheme works as follows: Each period there are $\bar{x}_{t}(s)$ households of type $s$ and revenues must be raised to finance $g_{t}$ units of government consumption ${ }^{12}$. Given that households are risk-averse, at the beginning of each period before the idiosyncratic processes are realized, they enter into contracts that equate the marginal utility of consumption of workers and non-workers regardless of the realizations of their shocks and, therefore, of their individual marginal productivities. Prescott and Townsend (1984) show that the full insurance allocation in an environment similar to this one can be supported as a competitive equilibrium with lotteries. In this paper I solve the centralized version of this problem.

12 Note that both measures of households and the sequence of government consumptions are identical to those that obtain in the limited insurance economy which has been solved first. 
Specifically, given the labor income tax rate, $\theta$, and the amount of government consumption, $g_{t}$, the social planner simultaneously determines the measure of households of each type who work in the market, $\bar{n}_{t}(s)$, the consumption levels for workers, $c_{1}$, and non-workers, $c_{0}$, that equate the marginal utilities of consumption across types, and the level of lump-sum taxes or transfers, $T(g, z)$, needed to balance the government budget. The contract also specifies that highly productive households are always chosen to work first, and that in those periods when only a fraction of the households of a given type are required to work, the workers are selected randomly amongst all households of that type. The main features of this model economy and of the problem solved by the planner are described in the subsections below.

\subsection{The household sector}

There is a continuum of households with total measure one. As was the case in the limited insurance economy, the households in this model economy order their random streams of consumption and leisure according to (5), and they are heterogeneous with respect to the realizations of a household-specific productivity shock, $s$. At each point in time the measure of households of type $s$ is $\bar{x}_{t}(s)$. The initial measure of household types is $\bar{x}_{0}$. To make this economy comparable with the limited insurance economy, I impose that $\bar{x}_{0}(s)=\sum_{a \in A} x_{0}(a, s)$ for every $s$.

\subsection{Information and production opportunities}

The properties and realizations of the stochastic processes, the timing of the information and the nature of the production technologies are identical to the corresponding ones of the limited insurance economy described above.

\subsection{The social planner's problem}

Given the realization of the economy-wide shock, $z$, the measures of households of each type, $\bar{x}(s)$, the labor income tax rate policy, $\theta$, and the amount of government consumption, $g$, each period the social planner determines the consumption allocations for workers and non-workers, $\left\{c_{0}, c_{1}\right\}$, the measures of workers for each type $\bar{n}(s)$, and the level of lump-sum taxes, $T$, that solve the problem described in (15)-(19) below. Note that since it is assumed that no assets are held in this economy, the social planner problem is static.

$$
\max _{c_{1}, c_{0}, n(s), T}\left\{\sum_{s} \bar{n}(s: T) u\left(c_{1}, \tau-1\right)+\sum_{s}[\bar{x}(s)-\bar{n}(s: T)] u\left(c_{0}, \tau\right)\right\}
$$

s.t.

$$
\sum_{s} \bar{n}(s: T) c_{1}+\sum_{s}[\bar{x}(s)-\bar{n}(s: T)] c_{0} \leq \sum_{s} \bar{n}(s: T) w(s, z)(1-\theta)-T
$$




$$
\begin{gathered}
g=\theta \sum_{s} \bar{n}_{t}(s: T) w(s, z)+T \\
\bar{n}(s: T) \leq \bar{x}(s)
\end{gathered}
$$

for $s=1,2, \ldots, n_{s}$.

$$
c_{0}, c_{1}, \bar{n}(s: T) \geq 0
$$

for $s=1,2, \ldots, n_{s}$. By solving the program above, the social planner is treating each household symmetrically and maximizing total utility. Since contracts are signed before the productivity shock is realized and since all households are ex-ante identical, I consider symmetry to be a reasonable choice of social weights for this economy ${ }^{13}$.

\section{The experiments}

To compare the aggregate fluctuations implied by the two insurance technologies explored in this paper, I carry out the following three computational experiments. Since in the U.S. throughout the 1926-90 period annual inflation rates averaged about 4 percent, in Experiment 1 I explore the business cycle properties of a model economy in which the annual inflation rate is 4 percent. I refer to this economy as the baseline economy ${ }^{14}$. To gain additional intuition about the behavior of this class of model worlds, in Experiments 2 and 3, I explore the business cycle implications of both lower and higher inflation rates. Specifically, in Experiment 2 the inflation rate is chosen to be zero and in Experiment 3 it is chosen to be 10 percent. Throughout the three sets of experiments, labor income is taxed at a rate of 25 percent. This value is chosen to roughly match average income taxes in the United States. The policy parameters for the three experiments are reported in Table 1. Note that even though the processes on $g$ are identical in the limited and in the full insurance economies of each experiment, they differ across experiments. Consequently, the process on government supply of the nominal as-

Table 1. Government policy parameters

\begin{tabular}{lll}
\hline & Inflation rate $(\varepsilon)$ & $\begin{array}{l}\text { Tax rate }(\theta) \\
\%\end{array}$ \\
\hline Experiment 1 & 4 & 25 \\
Experiment 2 & 0 & 25 \\
Experiment 3 & 10 & 25 \\
\hline
\end{tabular}

\footnotetext{
${ }^{13}$ Prescott and Townsend (1984) show that the Kuhn-Tucker conditions of this problem are sufficient for a maximum and that the solution is unique. A detailed description of the algorithm and the FORTRAN program used to solve this problem are available from the author upon request.

${ }^{14}$ Note that this rate of inflation implies a real rate of return on nominal assets of -4 percent, which is well below the intertemporal substitution rate of the model economy households.
} 
set, $a_{g}$, of the limited insurance economy, and the sequence of lump-sum taxes, $T_{t}$, of the perfect insurance economy also differ across experiments.

\subsection{Findings}

\subsubsection{The calibration exercise}

To calibrate the model economy I try different variances of the productivity shock until I match the fluctuations of U.S. output in the post-Korean war period. Table 2 reports the results of this exercise. Table 3 contains the corresponding set of statistics for the U.S. economy during the 1954-89 period as reported in Kydland and Prescott (1990). The fact that there is no capital accumulation in the model economy and the role played by government consumption should be kept in mind when evaluating these results. Some significant features of the cyclical behavior of the model economy are

Table 2. The cyclical behavior of the calibrated model economy (deviations from trend)

\begin{tabular}{lccccccccc}
\hline Variable $x$ & $\begin{array}{l}\text { Volatility } \\
\text { (\% std. dev. })\end{array}$ & \multicolumn{6}{l}{ Cross-correlation of output with } \\
\cline { 3 - 9 } & & $x(t-3)$ & $x(t-2)$ & $x(t-1)$ & $x(t)$ & $x(t+1)$ & $x(t+2)$ & $x(t+3)$ \\
\hline \multirow{2}{*}{ Output } & 1.74 & -0.10 & -0.09 & 0.12 & 1.00 & 0.13 & -0.09 & -0.10 \\
& $(0.002)$ & $(0.078)$ & $(0.083)$ & $(0.069)$ & $(0.000)$ & $(0.069)$ & $(0.085)$ & $(0.074)$ \\
Consumption & 0.59 & -0.14 & -0.13 & 0.06 & 0.81 & 0.42 & 0.22 & 0.11 \\
& $(0.001)$ & $(0.078)$ & $(0.081)$ & $(0.071)$ & $(0.027)$ & $(0.059)$ & $(0.085)$ & $(0.091)$ \\
Government & 5.24 & -0.08 & -0.08 & 0.13 & 0.98 & 0.04 & -0.18 & -0.16 \\
consumption & $(0.006)$ & $(0.077)$ & $(0.084)$ & $(0.068)$ & $(0.004)$ & $(0.064)$ & $(0.084)$ & $(0.070)$ \\
Hours & 1.46 & -0.08 & -0.07 & 0.13 & 0.95 & -0.04 & -0.23 & -0.19 \\
& $(0.002)$ & $(0.073)$ & $(0.082)$ & $(0.064)$ & $(0.012)$ & $(0.064)$ & $(0.086)$ & $(0.072)$ \\
Wage & 0.59 & -0.11 & -0.09 & 0.05 & 0.62 & 0.49 & 0.30 & 0.16 \\
& $(0.001)$ & $(0.081)$ & $(0.078)$ & $(0.076)$ & $(0.040)$ & $(0.047)$ & $(0.084)$ & $(0.099)$ \\
\hline
\end{tabular}

Table 3. The cyclical behavior of the U.S. economy: 1954-89 (deviations from trend) ${ }^{\mathrm{a}}$

\begin{tabular}{lllllllll}
\hline Variable $x$ & $\begin{array}{l}\text { Volatility } \\
(\% \text { std.dev. })\end{array}$ & \multicolumn{7}{l}{ Cross-correlation of the real GNP with } \\
\cline { 3 - 9 } & & $x(t-3)$ & $x(t-2)$ & $x(t-1)$ & $x(t)$ & $x(t+1)$ & $x(t+2)$ & $x(x+3)$ \\
\hline Output & 1.71 & 0.38 & 0.63 & 0.85 & 1.00 & 0.85 & 0.63 & 0.38 \\
Consumption $^{\mathrm{b}}$ & 0.84 & 0.53 & 0.67 & 0.77 & 0.76 & 0.63 & 0.46 & 0.27 \\
Investiment $^{\mathrm{c}}$ & 5.38 & 0.44 & 0.64 & 0.83 & 0.90 & 0.81 & 0.60 & 0.35 \\
Gvt purchases $^{\mathrm{d}}$ & 2.07 & -0.03 & -0.01 & -0.01 & 0.05 & 0.09 & 0.12 & 0.17 \\
Hours $^{\mathrm{e}}$ & 1.47 & 0.23 & 0.44 & 0.69 & 0.86 & 0.86 & 0.75 & 0.59 \\
Wage $^{\mathrm{f}}$ & 0.88 & 0.34 & 0.48 & 0.50 & 0.51 & 0.21 & -0.02 & -0.25 \\
\hline
\end{tabular}

aSource: Citicorp's Citibase data bank. Sample period: 1954:1-1989:4.

${ }^{\mathrm{b}}$ Non-durables and services.

${ }^{\mathrm{c}}$ Fixed investment.

${ }^{\mathrm{d}}$ Includes federal, state and local government purchases.

${ }^{\mathrm{e}}$ Household survey.

${ }^{\mathrm{f}} \mathrm{GNP} /$ hours (household survey). 
the following $i$.) in the model economy private consumption fluctuates 30 percent less, and government consumption 2.5 times more, than in the U.S. economy ${ }^{15}$, ii.) the fluctuations of hours in the model economy is surprisingly close to the fluctuations of hours in the U.S. economy, iii.) the model economy displays a high degree of contemporaneous correlation between output, hours, private consumption and government consumption, and $i v$.) the model economy displays a dampened propagation of the productivity shocks. This last result arises in part from the fact that, unlike capital accumulation, the nominal assets held in this economy for consumption smoothing purposes play no role in production.

\subsubsection{The aggregate fluctuations of the model economies}

\section{Fluctuations in output}

As can be seen from the first two rows of Table 4, fluctuations in both output, $y$, and hours of labor services, $h$, are larger under the limited insurance technology than under the full insurance technology. More specifically, aggregate output in the limited insurance economies of Experiments 1, 2 and 3 fluctuates, respectively, 25\%,21\% and $21 \%$ more than aggregate output in the corresponding full insurance economies ${ }^{16}$.

The intuition behind this result is the following: while the full insurance technology allows households to pool their household-specific components of risk contemporaneously, the limited insurance technology allows households to improve their life-time allocations of consumption and leisure individually by varying their asset holdings intertemporally. In this latter case

Table 4. Fluctuations in output, hours and productivity

\begin{tabular}{|c|c|c|c|c|c|c|}
\hline & \multicolumn{2}{|c|}{$e(z)=1.00$} & \multicolumn{2}{|c|}{$e(z)=1.04$} & \multicolumn{2}{|c|}{$e(z)=1.10$} \\
\hline & L. I $^{\mathrm{a}}$ & F.I. & L.I & F.I. & L.I & F.I. \\
\hline$\sigma_{\mathrm{y}}^{\mathrm{b}}$ & 2.583 & 2.062 & 1.744 & 1.439 & 1.353 & 1.111 \\
\hline$\sigma_{\mathrm{h}}$ & 2.188 & 1.622 & 1.455 & 1.104 & 1.085 & 0.811 \\
\hline$\sigma_{\mathrm{h}} / \sigma_{\mathrm{y}}$ & 0.847 & 0.787 & 0.834 & 0.767 & 0.802 & 0.730 \\
\hline$\sigma_{\mathrm{h}} / \sigma_{\mathrm{w}}$ & 3.753 & 2.787 & 2.479 & 1.900 & 1.836 & 1.393 \\
\hline$\rho(\mathrm{h}, \mathrm{w})$ & 0.605 & 0.679 & 0.340 & 0.398 & 0.235 & 0.249 \\
\hline
\end{tabular}

${ }^{\text {a }}$ L.I. is the abbreviation of limited insurance and F.I. is the abbreviation of full insurance. ${ }^{\mathrm{b}} \sigma_{\mathrm{x}}$ denotes the percentage standard deviation of logged, detrended $\mathrm{x}$.

15 These properties of the model economy are discussed at length in the subsection below.

${ }^{16}$ Prescott (1986), page 21, states that "a final example of an interesting and not yet answered question is how much would the behaviour of the Hansen (1985) indivisible labor economy change if agents did not have access to a technology to insure against random unemployment and instead had to self-insure against unemployment by holding liquid assets?". The computational experiments carried out in this paper are an attempt to provide a numerical answer to his question. 
households build up their nominal asset holdings in good times and deplete them when the times are bad in order to smooth out their streams of consumption in the presence of time-varying production opportunities. This increased labour when the sun shines and increased leisure when it rains accounts for the higher volatility of output and hours in this model economy. On the other hand, under the full insurance technology, households have no incentives to accumulate nominal assets and, consequently, they have neither a reason for additional work in good times, nor the possibility of financing consumption without work in bad times. Hence, fluctuations in both employment and output are smaller in this economy. Furthermore, by always requiring the highly productive households to work first, the contracts supported by the full insurance technology cushion the fluctuations induced by the household-specific productivity component even further.

\section{Fluctuations in hours and productivity}

Accounting for the cyclical behaviour of the labour market has always been considered one of the major challenges faced by equilibrium business cycle theory. The last three rows of Table 4 report three sets of statistics that describe the labor market fluctuations of the model economies. I find that in the limited insurance economies the relative fluctuations of hours and output are approximately $10 \%$ larger than in the corresponding full insurance economies. In the baseline limited insurance model economy the value for this statistic is $\sigma_{h} / \sigma_{y}=0.834$; the value reported by Kydland and Prescott (1990) for the U.S. economy using the household survey estimates of aggregate hours is $0.86^{17}$, while Christiano and Eichenbaum (1990) report a value of 0.62 for a model economy that includes indivisible labor, Rogerson (1988) employment lotteries and shocks to both technology and government consumption. I find that introducing limitations in the insurance technology increases the relative volatility of hours and output and therefore represents a move in the right direction.

The fourth row of Table 4 reports the volatility of hours relative to the average real wage, $w$, which is also the average productivity of labor. I find that the limited insurance technology entails a response of aggregate hours to changes in the average real wage that is about 30\% larger than the one that obtains under full insurance. This result, and the smaller correlation of hours and the average real wage reported in the fifth row of that same table, are implications of the different substitution and income effects that arise when variations in asset holdings are used to substitute for the consumptionsmoothing role of income insurance. The value for the relative variability of hours and productivity reported by Kydland and Prescott (1990) for the U.S. economy is $1.62^{18}$, while Christiano and Eichenbaum (1990) report a value of 1.36 for their indivisible labor two-shock model economy. Again, I find that

${ }^{17}$ Kydland and Prescott (1990) use Citicorp's Citibase quarterly data for 1954-1989. The value for the same statistic using the measure of hours reported in the business surveys is 0.96 .

${ }^{18}$ The value for this statistic using the measure of hours reported in the business surveys is 1.81 , 
introducing limitations in the insurance technology increases the volatility of hours relative to changes in the real wage, and, therefore, it also results in a move in the right direction along this dimension.

Finally, the last row of Table 4 reports the correlation of hours worked and the average real wage. As far as this statistic is concerned, Prescott (1986) implicitly acknowledges, and Christiano and Eichenbaum (1990) forcefully argue, that the key remaining deviation between theory and observations is, precisely, that technology driven real business cycle models present a large positive correlation between hours worked and the return to working, while in the U.S. economy both variables are virtually uncorrelated $^{19}$. The intuition is that in models where productivity shocks are the only source of aggregate fluctuations, the demand for labor shifts about about a static, upward sloping labor supply curve and, therefore, this generates a large positive correlation between labor services and their price. Christiano and Eichenbaum (1990) go on to show that including shocks to government consumption as an additional source of fluctuations improves the performance of the model economy significantly, and they report a value of 0.73 for their two-shock indivisible labor model economy.

The results reported here show that the limited insurance technology reduces the correlation of hours and the real wage in about $10 \%$. We have already seen that implementing the limited insurance arrangement implies large fluctuations in government consumption, hence it is not surprising that the values reported here are considerably smaller than those that obtain in the standard one-shock real business cycle models. What is more interesting is to note that the correlation of hours worked and the real wage is consistently smaller in the limited insurance than in the full insurance economies, again as the result of the different income and substitution effects implied by each arrangement. These results suggest that the inclusion of uninsured components of household-specific income risk in equilibrium business cycle models would also improve their performance along this dimension.

\section{Fluctuations in private and government consumption}

Table 5 reports the relative fluctuations of output, $y$, private consumption, $c$, and government consumption, $g$. I find that fluctuations in private consumption relative to income are consistently smaller in the limited insurance economies. I conclude therefore that the limited insurance technology analyzed in this paper supports smoother streams of consumption relative to income than the full insurance technology. It should be noted, however, that this consumption smoothing is obtained at the expense of greater variability of hours relative to income (see the third row of Table 4) and, hence, of a greater variability of leisure relative to income.

As far as the volatility of government consumption is concerned, I find that implementing the limited insurance arrangement entails large fluctua-

${ }^{19}$ Christiano and Eichenbaum (1990) use Citicorp's Database for 1955-83 and report for this variable a value of -0.20 for the U.S. economy. 
Table 5. Fluctuations in private and government consumption

\begin{tabular}{|c|c|c|c|c|c|c|}
\hline & \multicolumn{2}{|c|}{$e(z)=1.00$} & \multicolumn{2}{|c|}{$e(z)=1.04$} & \multicolumn{2}{|c|}{$e(z)=1.10$} \\
\hline & L. $I^{\mathrm{a}}$ & F.I. & L.I & F.I. & L.I & F.I. \\
\hline$\sigma_{\mathrm{y}}^{\mathrm{b}}$ & 2.583 & 2.062 & 1.744 & 1.439 & 1.353 & 1.111 \\
\hline$\sigma_{\mathrm{c}} / \sigma_{\mathrm{y}}$ & 0.264 & 0.347 & 0.338 & 0.471 & 0.443 & 0.596 \\
\hline$\sigma_{\mathrm{g}} / \sigma_{\mathrm{y}}$ & 3.104 & 3.894 & 3.009 & 3.625 & 2.851 & 3.484 \\
\hline
\end{tabular}

${ }^{a}$ L.I. is the abbreviation of limited insurance and F.I. is the abbreviation of full insurance.

${ }^{\mathrm{b}} \sigma_{\mathrm{x}}$ denotes the percentage standard deviation of logged, detrended $\mathrm{x}$.

tions in government consumption. From the consolidation of the individual households' budget constraints and the market clearing condition, one can easily show that:

$$
g=\theta y+\left(a^{\prime}-\frac{a}{e}\right)
$$

i.e., that government consumption equals government revenues plus the aggregate addition to private savings. This addition to private savings in the limited insurance economies plays the role of investment in standard business cycle models and, as is the case of investment, presents fluctuations that range from 2.5 to 3 times the variations in income. When comparing both classes of economies, I find that the relative volatility of government consumption is roughly $20 \%$ smaller in the limited insurance economies than in the corresponding full insurance economies. This result follows from the fact that the sequences of government consumptions are identical across both types of economies while output is more volatile under the limited insurance arrangement.

\section{Concluding comments}

In this paper I evaluate the business cycle implications of uninsured idiosyncratic risk and liquidity constraints. To this purpose I compare the aggregate fluctuations of two model economies that differ in the insurance technologies available to households only. I find that under the limited insurance technology output and hours are more volatile, the relative fluctuations of hours and output is larger, hours worked are less correlated with the average real wage, and consumption paths are smoother than those that obtain under the full insurance technology. One interpretation of these results is that including uninsured components of aggregate risk into equilibrium business cycle models would most likely improve their performance along those margins.

An extension of this research is to relax the extreme form of liquidity constraints analyzed in this paper and to explore the business cycle implications of assuming that there is an explicit financial intermediation technology that allows for some borrowing. One step in this direction has already been 
taken in Díaz-Giménez et al. (1992). If bankruptcy and any other disruptive effects that arise from the financial intermediation sector are precluded, it seems safe to conjecture that, if borrowing were allowed, the aggregate fluctuations of the limited and full insurance economies would be closer. Another important extension of this line of research would be to model capital accumulation. Conceptually this extension is straight forward, but, technically, it requires to make prices dependant on the distribution of households. Two attempts to solve this difficult computational issue can be found in Krussell and Smith (1994) and in Castañeda et al. (1995). Once the computational problems are solved, it would be interesting to explore the business cycle properties of an economy where nominal assets are held for consumption smoothing purposes and where capital is used as an input in production.

\section{Appendix 1}

\section{a. Defintions of the model aggregates}

For each simulation of the model economies I compute the following aggregates:

1. Aggregate real gross income

$$
y=\sum_{a, s} w(s, z) n(a, s, z) x(a, s)
$$

2. End-of-period aggregate real asset holdings ${ }^{20}$

$$
m=\sum_{a, s} a^{\prime}(a, s, z) x(a, s)
$$

3. Aggregate real consumption

4. Aggregate employment ${ }^{21}$

$$
c=\frac{m_{-1}}{e(z)}+y(1-\theta)-m
$$

$$
h=\sum_{a, s} n(a, s, z) x(a, s)
$$

\section{b. Definitions of quarterly time series}

I then used the model aggregates to construct quarterly time series for some of the basic macroeconomic variables. In so doing, I followed as closely as possible the procedures actually used for U.S. data. Flows are therefore quoted annually. Subscript $i$ denotes the $i$-th subperiod of each quarter. Since the model period was chosen to be one-eighth of a year, $i=1,2$. I computed the following variables:

\footnotetext{
20 This aggregate was only computed for the for the limited insurance economy.

21 Since the measure of households is 1 , levels and rates are equal
} 
1. Real output

2. Real consumption

$$
y=4\left(y_{1}+y_{2}\right)
$$

$$
c=4\left(c_{1}+c_{2}\right)
$$

3. Real government consumption

$$
g=y-c
$$

4. Aggregate labor input

$$
h=4\left(h_{1}+h_{2}\right) 0.45
$$

5. Average labor compensation

$$
w=y / h
$$

\section{References}

1. Atkeson, A., Lucas Jr. R. E.: On efficient distribution with private information. Review of Economic Studies forthcoming (1992)

2. Bewley, T.: The optimum quantity of money. In: Models of Monetary Economics, Kareken J., Wallace N.(eds) Federal Reserve Bank of Minneapolis, pp. 169-210 (1980)

3. Castañeda A., Díaz-Giménez J., Ríos-Rull J. V.: Unemployment spells and income distribution dynamics. Mimeo (1995)

4. Christiano, L. J., Eichenbaum M.: Current real business cycle theories and aggregate labor market fluctuations. American Economic Review 82, 430-450 (1992)

5. Delong, B., Summers L. H.: Are business cycles symmetrical? In: R. Gordon, ed., The American Businesss Cycle: Continuity and Change. Chicago: University of Chicago Press 1977

6. Díaz-Giménez, J., Prescott E C.: Real returns on government debt: a general equilibrium quantitative exploration. European Economic Review forthcoming (1996)

7. Díaz-Giménez, J., Prescott E C, T. Fitzgerald, Alvarez F,: Banking in computable general equilibrium economies. Journal of Economic Dynamics and Control, 16, 533-559 (1992)

8. Green, E.: Lending and the smoothing of uninsurable income. In: E. C. Prescott and N. Wallace (eds.) Contractual Arrangements for Intertemporal Trade. Minnnesota Studies in Macroeconomics (1987)

9. Green, E., Oh S. N.: Contracts, constraints and consumption. Review of Economic Studies forthcoming (1992)

10. Hansen, G. D.: Indivisible labor and the business cycle. Journal of Monetary Economics 16, 309-328 (1985)

11. Imrohoroglu, A.: Costs of business cycles with indivisibilities and liquidity constraints. Journal of Political Economy 97, 1364-1383 (1989)

12. Imrohoroglu, A.: The welfare cost of inflation under imperfect insurance. Journal of Economic Dynamics and Control 16, 79-91 (1992)

13. Imrohoroglu, A., Prescott E. C,: Evaluating the welfare effects of alternative monetary arrangements. Federal Reserve Bank of Minneapolis Quarterly Review (Summer), pp. 3-10 (1991)

14. Kydland, F. E., Prescott E. C.: Time to build and aggregate fluctuations. Econometrica 50, $1345-1370$ (1982)

15. Kydland, F.E., Prescott E. C.: Business cycles: Real facts and a monetary myth. Federal Reserve Bank of Minneapolis Quarterly Review (Spring) 3-18 (1990)

16. Krusell, P., Smith A.: Aggregation in a Macroeconomic Model with Heterogeneous Consumers. Mimeo (1994)

17. Lucas, R. E. Jr.: Understanding business cycles. Carnegie-Rochester Conference Series on Public Policy 5, 7-29 (1977) 
18. Lucas, R. E. Jr.: Equilibrium in a pure currency economy. In: J. Kareken, N. Wallace (eds.) Models of Monetary Economics. Federal Reserve Bank of Minneapolis, pp. 131-145 (1980)

19. Lucas, R. E. Jr.: Models of Business Cycles. New York: Basil Blackwell 1987

20. Mace B. J.: Full insurance in the presence of aggregate uncertainty, Journal of Political Economy 99, 928-956 (1992)

21. Marcet, A., Marimon. R.: Recursive formulation of dynamic contracts with non recursive constraints. Mimeo, Universitat Pompeu Fabra (1995)

22. Phelan, C.: Exploring the quantitative implications of Dynamic, incentive-constrained optima. Working Paper, University of Chicago (1989)

23. Phelan, C., Townsend. R. M. Computing the optimal insurance-incentive tradeoff for multiperiod, information constrained economies. Review of Economic Studies forthcoming (1992)

24. Prescott, E. C.: Theory ahead of business cycle measurement Carnegie-Rochester Series on Public Policy 25, 11-44 (1986)

25. Prescott, E. C., Townsend R. M.: Pareto optima and competitive equilibrium with adverse selection and moral hazard. Econometrica 52, 21-45 (1984)

26. Ríos-Rull, J. V.: Models with heterogeneous agents. Chapter 4 of Frontiers of Business Cycle Research. T. Colley (ed.) Princeton University Press 1995

27. Rogerson, R. D.: Indivisible labor, lotteries, and equilibrium. Journal of Monetary Economics 21, 3-16 (1988)

28. Scheinkman, J., Weiss., L.: Borrowing constriants and aggregate economic activity. Econometrica 54, 23-45 (1986)

29. Zeldes, S. P.: Consumption and liquidity constraints: an empirical investigation. Journal of Political Economy 97, 305-46 (1989) 